\title{
A Reflection and Optimization of the Cooperative Instruction Mode between University Libraries and Departments from the Perspective of Innovative Education
}

\author{
Xiaohong Qin ${ }^{a^{*}}$ and Jingfeng Zhao ${ }^{\mathrm{b}}$ \\ School of Economics and Management, Northwest University, \\ 229 Taibai N. Rd. Xi'an, Shaanxi, China 710069 \\ a34462423@qq.com, bzhaojingfeng369@sina.com
}

Keywords: Educational innovation; Cooperation between university libraries and departments; Educational cooperation; Reflection; Optimization

\begin{abstract}
The key to solve the problem of the emergence of distortion and deviation that docks the universities talents and the needs of social reality lies in the mode of innovative personnel training. This paper reflects the teaching mode issues of colleges and traditional library, and on this basis, so as to innovate in our school education, and makes a exploration and research on the existing practical issues that the cooperative instruction mode between libraries and departments that exists, the ideal situation and the path to achieve this.
\end{abstract}

\section{Introduction}

Professor Bollinger, the Colombia University President once put it, "a 21st century-oriented college education is no longer just simple dissemination of knowledge to the students, but also seriously explore the global challenges through extensive enovation to interdisciplinary area to guide students 'breadth and depth of knowledge, so that it would respond to the future life challenges."

For many years, education in colleges and universities in our country have shown reversed separatist tendencies between the teaching practice and theory, which caused that most of the college students' abilities on hand practice is weak, lack of capacity for innovation, entering society or unemployment, or cannot quickly adapt to the urgent situation.

The 17th national congress of Communist party put forward specifically: "to improve the capability of independent innovation, so that we can build up an innovation-oriented country. This is the core development strategy in our country, and also is the key to improve comprehensive national strength." To create into an innovation-oriented country, we need to cultivate a large number of innovative talents. Facing the malpractice of traditional teaching embodied in the past, we certainly puts forward a new subject in colleges and universities, so this paper will explore how to cultivate innovative talents to meet the needs in today's society.

\section{The Proposal of Cooperation Model between University Libraries and Departments under the Environment of Innovative Education}

Reflection on the Traditional Library-Conducted Teaching Model. At this stage, our libraries of higher education bear education on students' information literacy mainly through literature retrieval courses, while in traditional teaching mode, what kind of teaching method that library education use is to teach first and then practice on the computer and then the assessment, this mode mainly treat teachers to impart knowledge retrieval and searching method as the primary purpose of teaching, but students learn in a state of passive acceptance, and they merely can master simple literature search tools and techniques.

Innovative education requires students to have the abilities of information analysis and identification of strategy to help them, and then enhance learning and study. The library literature retrieval course should not become innovative education blind, but actively obtain documents to professional courses lectures, projects, exams so as to enhance the ability to solve practical problems 
and raise students' enthusiasm and awareness, and increase the ability to put information problems into practice.

Reflection on the Single Teaching Mode of Colleges. For four-year colleges and universities students who receives full-time education, in actual teaching it becomes a school education for three years, and then find a job in a year. In this mode, teachers teach and students passively accept the knowledge; in teaching methods and classroom teaching, practice and theory are often in a disjointed state; in teaching methods, it is lack of guidance and instill this knowledge systematic theory-based teaching, many theories and no ability to bring quality cultural grab shallow, an important part of the inevitable result of the accumulation of hard to digest, practical and significant accumulation no embarrassment.

At present, many teachers often limit themselves to their own disciplines, and some of them are lack of horizontal communication and with other fellow teachers, and mutual assistance. But innovation and education, a lot of practice each discipline cannot be completed successfully, but the cross and integration practice multidisciplinary expertise perspective. Teachers must be aware that teaching is more than a tool to train and indoctrinate, but also as a means of cognitive development, the use of scientific teaching mode is to ensure students' abilities to innovate.

Innovative Education Requires the Cooperation between Libraries and Academies. Colleges and universities are an important carrier of personnel training, which carry the important task of personnel training, and library, an important place to cultivate the students' information abilities, also bear important responsibilities. Based on the reflection on the specific problems and education mission, the "National College Students Innovation Experiment Program" implemented by the Ministry of Education implemented in 2006, had started 15,000 research projects, which aims to explore and to establish teaching model through the problems and issues, design core, so as to inspire innovative thinking and cultivate college students' ability to solve problems in practical use.

Currently, many universities have the project that 211 undergraduates innovative team has started to construct. To build a innovative team, schools will achieve more development advantages, and to develop innovative education, teachers need to have a solid guarantee, while demand in various sectors, have an effect on the formation a team of library teachers, the overall design, unified planning and a more efficient team, which increases the exploration of problem, design and practicality of gravity, the learning process as the main guide of the problem unfolded, as well as creative thinking, innovation and innovation ability, to make them confirm with the social needs.

\section{The Status of Co-Teaching between Library and Academy Institutions under the Innovative Educational Background}

Since the "College Students' Innovative Experiment" project started in 2008, to change the shortcomings of the traditional teaching model, and also involved in "College Students Innovation Experiment Team" teaching and research project between academies, which aims to make full advantages of the information literacy education by library. Through innovative education, the cooperation's practice between our school academies and libraries, cooperation is still the form than substance. In this way, we need to reflect on the cooperation mode between libraries and academies to and find solutions to problems, so as to find synergies to improve the teaching path and to realize the true value of cooperative education.

The Disciplinary Boundaries is One Kind of Limitation to the Cooperation between Libraries and Academies. In education, due to the surge of knowledge's disciplinary differentiation, this lead that teachers of various departments lack the necessary communication on academic exchanges and research, and has already formed a strict disciplinary boundaries. Only we continue to strengthen the teaching of theoretical knowledge and desalination of personal knowledge of other disciplines, inherent discipline, to combine with the issue of teacher evaluation system so that teachers only teach the discipline to several persons, and then virtually form a consciousness "cooperation is not necessary".

The Teacher's Incoordinate Identity of the Cooperation between Libraries and Academies Leads to a Result of Lower Effectiveness. School libraries appears as the second class, which 
resulting in school leaders' inadequate attention as that the library have a priority of low position, thereby hindered development, and lack of voice in the process to deal with the major event. Currently, the real situation of library literature retrieval course is not optimistic, and the Education Ministry tends to artificially cut the curriculum, it can be studied literature retrieval teaching most university libraries network can be seen, the basic principles of abdication compulsory elective courses, leading to students' ability to obtain information in the information age presented the opposite trend weakened. In the minds of teachers, library is just to borrow but still provide services, rather than academic institutions. Due to unequal status, it results in a negative attitude of cooperation, so effective communication and communication in teaching have little chance to make a substantive cooperation.

The Teachers are Lack the Sense of Cooperation between the Libraries and Academy, so that the Operability of Cooperation is Reduced. Education alone mode co-teaching in-depth discussions of the meaning and value no clear understanding, besides, the main and supporting characters exposed in front of the other subject teachers fear that cooperation personal identity insufficient to make innovative education, especially not really interact linkage effectively. UNESCO has made a statement: talents in twenty-first century have to learn to learn, learn to survive, and learn to cooperate. Cooperation is not only conducive to teaching and to improve students' innovation, but also help to improve teachers' teaching ability. Whether teachers library, someone who become a teacher have conscious reflection, and they should recognize that different teachers have different professional and academic backgrounds, cognitive structure, way of thinking and teaching experience, teachers' cooperation can achieve complementary experience and resources sharing, and personal cognitive structure will be improved.

The Lack of a Sound System Results that Co-Teaching cannot Continue to Persist. Since the two years from researchers students' innovative experiment project team was conducted, there are still rules and norms, the ideal place to the next in the system more effective policy guidance, many legal systems need to incorporate the rights and obligations of stagnation, In addition to specification. to protect the future of development cooperation and better teaching mode, in addition to college should establish a win-win concept of a museum cooperation, the establishment and improvement of a more rational system is necessary and propulsion system can not only ensure the smooth development of cooperation but also an important part to establish long efficient mechanisms.

\section{The Practical Issues that the Cooperative Instruction Mode between Libraries and Departments under the Perspective of Innovative Teaching Model}

The innovative education will not happen overnight, in order to be able to find better strategy and development path of cooperation between libraries and departments need to focus on the following aspects of the problem.

Be Sure to Highlight the Subjective Dynamic Role of Students. In the role of traditional teaching philosophy, teacher is to pass the main traditional teaching knowledge, and this knowledge transfer mode imprisons students' thinking and development. Innovative education, museum school teachers must have role transposition, and establish a philosophy of education "student-centered, practice-focused, with talent as the goal", so that students will become the subject of educational innovation, and become the theoretical study and practical skills or this will give the students the knowledge generated, frame interlinkages between body, change from passive to active learning the whole pattern of knowledge and knowledge have a clear understanding that the student is always the subject, and teachers are the organizers, they should not only ask questions as a method to solve the problem, the feasibility of the method, the pros and cons of other methods by students to complete, with full respect for the students. For each of their proposals cannot but make improper comments, but to guide them through experiments to make verification.

Library Teacher Must Strengthen Their Initiative. At this stage, especially in the era that digital resources update continuously, and the update of academic library resources is very fast. Because the teachers' professional task is more arduous, and they cannot keep an eye on the development of library resources, update status, so library teachers should take the initiative to date 
library resources, academic achievements at home and abroad, patents, standards, conference papers and other information that push to the professional teachers' department. During the push, avoiding falls, non-selective referral and response information to identify, analyze, categorize, to avoid the formation of spam, teacher resources, teacher need accurate initiative to push, to achieve a win-win faculties, support teachers' cooperation .

Focus on the Unity of Cooperative Teaching in the Aspect of Design. The traditional curriculum design grasp the overall gravity, which based on a single curriculum-based teaching, but ignoring the correlation between each course insufficient integration of knowledge integrity, comprehensive application are lacking. Cooperation with Hospital should become information courses, and professional courses for relevant professional architecture major courses lay extensible foundation. First, the implementation of 30 percent of modular courses, information-based class modules. The module is teaching information literacy education into student curriculum, knowledge and provide growth for professional learning ability. Secondly, 50\% of the course modules. The module theoretical courses and practical courses, professional courses module lays the professional knowledge, ability and quality on the basis of innovative talents should have composition lessons. Third, 20\%, the module expansion process. The module consists of the relevant professional disciplines, its teaching goal is to lay the basis for more extensive professional training on innovative talents, strengthen personnel training and flexible curriculum. In modular form, curriculum unified architectural design of both proposed division of labor and cooperation to help students adapt to the cultural and creative ability.

The Practice of Teachers Faculty of Its Efforts to Optimize as Carrier. We should optimize the practical ability of college teachers and take them as the practical teaching carrier. If teachers are lack of practical knowledge, it is impossible to understand the professional skills and fail to cultivate innovative talents. Currently, the Department is teaching teachers to pay more attention to theoretical study, research, and several teachers involved in teaching in the past, which led to the use of teachers' professional knowledge application ability of a lack of education. No teacher professional practice teaching is difficult to apply the expertise to teach students a vivid, emphasizing theory and practice cannot be ignored encourage contact between teachers and teachers' professional practice.

To Optimize the Affordable Substance of Innovative Education. It needs a good environment to implement innovative teaching mode, and we also need funds as guarantee. At this stage, much investment in higher education innovation fund, the basic problem is that the form of student teachers to participate in staged practice, innovative personal feeling is not easy to achieve. Therefore, strengthening the innovative talents, there is no corresponding capital investment, innovation and education may become a river without water, tree without root.

\section{Conclusion}

Based on the above, institutions of higher learning under the perspective of innovative education, there still remains many problems to be solved in the process of cooperation between library and academy, therefore, we need to be further optimize and reflect before complete. This paper makes a main specific analysis, so as to find a way to solve the problem, and then take a reflection and optimize the real work.

\section{References}

[1] Optimization and Innovation of under the horizon of New technologies force Library Education, Zhang Guojie - "Library Research" --2013.

[2] On the University Library Service Innovation under the Perspective of Learning - On Innovation path of Qingdao Technical College Library Service, Hu Ronghua, Wang Yun Qingdao Vocational and Technical College Journal --2013.

[3] The Practical Teaching Philosophy Innovation in Ideological and Political Classroom under the Horizon of MOOC, Wang Chengming - Beijing City University Journal --2015. 
[4] The Innovation of Ideological and Political Education Concept under Perspective of Humanism Teaching, Wang Meiyan - "Intelligence" --2014.

[5] To Analyze the Ideological and Political Theory Teaching Model Innovation from the Macro Perspective, Kou Shufang - "The Science and Education Digest" --2014. 